\title{
Phenotypic Characterization \& Determination of the Antibiotic Susceptibility Pattern of Clinical Isolates of Pseudomonas spp. Collected from Various Diagnostic Centers of Dhaka city, Bangladesh
}

\author{
Md. Aftab Uddin ${ }^{1}$ \\ Assistant Professor, Department of Microbiology, Stamford University Bangladesh, Dhaka, Bangladesh ${ }^{1}$
}

\begin{abstract}
Pseudomonas spp. is one of the foremost etiological agent causing severe infections of hospital admitted patients. This study was carried out to monitor the drug sensitivity patterns of the phenotypically identified Pseudomonas spp. collected from a nmber of admired diagnostic centers of Dhaka city, Bangladesh. A total of 50 non-duplicate isolates were characterized from various patients having diverse age groups and sex. The microorganisms found from varied specimens (i.e. urine, pus, sputum, ear secretions, wound swabs) were identified by a number of phenotypic and biochemical tests. Antibiotic susceptibility patterns against 20 different antibiotics were evaluated by the Agar-discdiffusion method to comprehend antibiotic resistance profile of the isolates. All the isolates were presumptively detected as Pseudomonas spp. The female patients (68\%) were likely to be more susceptible to the infections caused by Pseudomonas spp. than their male counterparts (32\%). Most of isoltaes showed multi-drug resistant (MDR) property. The highest resistance was recorded against amoxyclav $100 \%$, nitrofurantion $100 \%$, cotrimoxazole $100 \%$, cefuroxime $98 \%$, azithromycin $92 \%$, ceftriaxone $86 \%$, tygecycline $78 \%$ and nalidixic acid $70 \%$. Thee findings of this study showed that colistin was the most effective drug for the inhibition of Pseudomonas spp. followed by piperacillin, meropenem and amikacin.
\end{abstract}

Keywords: Pseudomonas spp., multi-drug resistant, effective drug.

\section{INTRODUCTION}

Pseudomonas is an aerobic, motile, Gram-negative bacterium and has caused trouble in diverse hospital acquired infections such as pneumonia, infection of urinary tract and skin and in severe burns. They are also one of the major causative agent for producing infections among immunosuppressed persons [1-3]. Pseudomonas spp. having multidrug resistant properties is particularly connected with augmented mortality because of the lack of options in healing choices [4].

Some of the mechanisms of drug resistance by Pseudomonas are considered to be the expression of aminoglycoside modifying enzymes, syntheis of biofilm and extensive range of $\beta$ lactamases along with mutations in DNA gyrase and topoisomerase [5]. It is considered to be the fifth frequent pathogen among nosocomial infection causing microorganisms and responsible for $10 \%$ of all hospital acquired infections [6]. In the context of Bangladesh, it is third in position and produces a number of infections [7].

An immense challenge stay alive if there is an appearance of Multi Drug Resistant (MDR) Pseudomonas as medical practitioners are left with restricted therapeutic options. In any health care setup, preceding information about the antibiotic susceptibility profile against frequently suggested drugs would facilitate the clinicians to choose suitable antimicrobial agents against these resistant strains. The current study therefore was performed to spot the antibiogram profile of the clinical isolates of Pseudomonas spp. along with their phenotypic characterization at Department of Microbiology, Stamford University Bangladesh. 


\section{MATERIALS AND METHODS}

\section{Collection of Samples}

The samples were collected between the periods of October 2020 to November 2020. The samples were collected from two diagnostic centers of Mirpur and Dhanmondi of Dhaka city, Bangladesh. A total of 50 clinical isolates of Pseudomonas spp. were collected from different types of clinical samples from suspected individuals of various age and gender groups. Sample processing and transportation were maintained as per WHO guidelines [8]. All experiment was performed in the laboratory of Department of Microbiology, Stamford University Bangladesh.

\section{Isolation and confirmation of Pseudomonas spp.}

Pure culture of Pseudomonas spp. was isolated and preserved using Cetrimide aga (CA). Collection of all the strains was done aseptically and transferred into Cetrimide aga (CA). The collected samples were incubated overnight at $37^{\circ} \mathrm{C}$ for 24 hours and were subjected for additional investigation.

\section{Microscopic analysis}

Bacterial size, shape, and staining characteristics were performed through microscopic analysis of the isolates [9]. Gram staining procedure was done for the primary identification of the isolates, followed by different biochemical tests. Cultural and morphological characteristics of the bacterial isolates were presumptively confirmed in accorance to standard microbiological protocols [10].

\section{Biochemical test for the confirmative identification}

All isolated bacteria were identified by standard laboratory biochemical tests according to the methods described by Collee et al., 1996 (11). The biochemical tests for Pseudomonas spp. were indole test, MR-VP test, coagulase test, catalase test, citrate test, motility test and urease test.

\section{Determination of antimicrobial susceptibility by disk diffusion method}

Pure culture of Pseudomonas spp. collected from different clinical samples was chosen for determining the antimicrobial susceptibility pattern against a different group of antibiotics such as Amikacin (30 $\mu \mathrm{g})$, Amoxyclav (30 $\mu \mathrm{g})$, Azithromycin $(30 \mu \mathrm{g})$. Cefixime $(5 \mu \mathrm{g})$, Ceftazidime $(30 \mu \mathrm{g})$, Ceftriaxone $(30 \mu \mathrm{g})$, Cefuroxime $(30 \mu \mathrm{g})$, Ciprofloxacin $(5 \mu \mathrm{g})$, Colistin $(10 \mu \mathrm{g})$, Gentamycin $(30 \mu \mathrm{g})$, Imipenem $(10 \mu \mathrm{g})$, Meropenem $(30 \mu \mathrm{g})$, Nalidixic acid $(30 \mu \mathrm{g})$, Nitrofurantoin $(300 \mu \mathrm{g})$, Cotrimoxazole $(30 \mu \mathrm{g})$, Piperacillin $(110 \mu \mathrm{g})$, Doripinum (), Tigecycline $(30 \mu \mathrm{g})$, Levofloxacin $(30 \mu \mathrm{g})$ and Cepepime () by Kirby Bauer disc diffusion method [12] as recommended by clinical and Laboratory Standards Institute (CLSI) guideline 2013.

\section{RESULTS}

In this study, all suspected plates were screened for the existence of yellow-green colors colonies of Pseudomonas spp. on CA media. All assumed Pseudomonas spp. isolates were confirmed by Gram staining, microscopic analysis and biochemical tests. Table 1 demonstrates the biochemical test results of all presumptive Pseudomonas spp. isolates.

\begin{tabular}{|c|c|c|c|c|c|c|c|c|c|c|}
\hline \multicolumn{11}{|c|}{ Table 1: Biochemical tests for the bacterial isolates } \\
\hline Assumed & $\begin{array}{l}\text { Coagul } \\
\text { ase } \\
\text { Test }\end{array}$ & $\begin{array}{c}\text { Indole } \\
\text { Test }\end{array}$ & $\begin{array}{l}\text { MR } \\
\text { Test }\end{array}$ & $\begin{array}{c}\text { VP } \\
\text { Test }\end{array}$ & $\begin{array}{c}\text { Citrat } \\
\text { e } \\
\text { Test }\end{array}$ & $\begin{array}{c}\text { Oxidas } \\
\text { e } \\
\text { Test }\end{array}$ & $\begin{array}{c}\text { Catal } \\
\text { ase } \\
\text { Test }\end{array}$ & $\begin{array}{l}\text { Ureas } \\
\text { e }\end{array}$ & Motility & $\begin{array}{c}\text { Nitrate } \\
\text { Reduction } \\
\text { Test }\end{array}$ \\
\hline Organism & - & - & - & - & + & & + & Test & + & + \\
\hline $\begin{array}{l}\text { Pseudomon } \\
\text { as spp. }\end{array}$ & & & & & & & & + & & \\
\hline
\end{tabular}




\section{International Advanced Research Journal in Science, Engineering and Technology}

Vol. 7, Issue 12, December 2020

DOI 10.17148/IARJSET.2020.71201

MR = Methyl red, VP =Voges-Proskauer,

Control organism: Pseudomonas aeruginosa ATCC® 27853

\section{Age \& sex distribution among study population}

A total of 50 patients of suffering from suspected pseudomonad infections were included in the study during October 2020 to November 2020. 16 (32\%) respondents were males while the remaining 34 (68\%) were females between age group of 1-90 years.

Table 2: Distribution of age and sex among respondents

\begin{tabular}{ccccccc}
\hline SL & Age & Total & Male & \% & Female & $\%$ \\
\hline 1 & 1 to 10 & 3 & 2 & 67 & 1 & 33 \\
2 & 11 to 20 & 2 & 1 & 50 & 1 & 50 \\
3 & 21 to 30 & 5 & 2 & 40 & 3 & 60 \\
4 & 31 to 40 & 7 & 4 & 57 & 3 & 43 \\
5 & 41 to 50 & 7 & 2 & 28 & 5 & 72 \\
6 & 51 to 60 & 9 & 2 & 22 & 7 & 78 \\
7 & 61 to 70 & 9 & 1 & 11 & 8 & 89 \\
8 & 71 to 80 & 4 & 0 & 0 & 4 & 100 \\
9 & 81 to 90 & 4 & 2 & 50 & 2 & 50 \\
7 & Total & 50 & 16 & 32 & 34 & 68 \\
\hline
\end{tabular}

A total 50 patients either sex (male-16 and female-34) with the respective ratio of 32:68 between age group of 1-90 years were included in this study (Table 2). Here minimum age was 2 months and maximum age was 85 years old. Table 2 shows that the incidence of disease is higher in females than male and incidence of infection was much higher in the patients having age group 51 years to 70 years age groups when compared to other age groups. The rate of infection seems to vary randomly according to age without any selective pattern, although, the tendency of getting affected by different pseudomonad infections seem to be higher in between the ages from 51-70 years old whereas the lowest prevalence rate was observed between the age group from 1-20 years old according to the present study findings.

50 clinical isolates of Pseudomonas spp. were subjected to antimicrobial resistance test against different commercial antibiotics. With the $100 \%$ resistance against amoxyclav, nitrofurantion and cotrimoxazole demonstrated as the most ineffective antimicrobial followed by cefuroxime $98 \%$, azithromycin $92 \%$, ceftriaxone $86 \%$, tygecycline $78 \%$ and nalidixic acid $70 \%$. However, colistin was the most effective drug against Pseudomonas spp. followed by piperacillin, meropenem and amikacin. The overall result of antibiotic se profile has been summarized in Table 3 .

Table 3: Overall antibiobic susceptibity pattern of Pseudomonas spp.

\begin{tabular}{|c|c|c|}
\hline SL & $\begin{array}{c}\text { Antipsudomonal antibiotics } \\
\text { tested }\end{array}$ & $\begin{array}{c}\text { \% No. of sensitive isolates } \\
(\mathbf{n}=\mathbf{5 0})\end{array}$ \\
\hline 1 & Amikacin $(30 \mu \mathrm{g}$ & 86 \\
\hline 2 & Amoxyclav $(30 \mu \mathrm{g})$, & 0 \\
\hline 3 & Azithromycin $(30 \mu \mathrm{g})$. & 8 \\
\hline 4 & Cefixime $(5 \mu \mathrm{g})$ & 88 \\
\hline 5 & Ceftazidime $(30 \mu \mathrm{g})$ & 8 \\
\hline
\end{tabular}




\section{International Advanced Research Journal in Science, Engineering and Technology}

Vol. 7, Issue 12, December 2020

DOI 10.17148/IARJSET.2020.71201

\begin{tabular}{|c|c|c|}
\hline 6 & Ceftriaxone $(30 \mu \mathrm{g})$ & 14 \\
\hline 7 & Cefuroxime $(30 \mu \mathrm{g})$ & 2 \\
\hline 8 & Ciprofloxacin $(5 \mu \mathrm{g})$ & 80 \\
\hline 9 & Colistin $(10 \mu \mathrm{g})$ & 96 \\
\hline 10 & Gentamycin $(30 \mu \mathrm{g})$ & 74 \\
\hline 11 & Imipenem $(10 \mu \mathrm{g})$ & 84 \\
\hline 12 & Meropenem $(30 \mu \mathrm{g})$ & 86 \\
\hline 13 & Nalidixic acid $(30 \mu \mathrm{g})$ & 30 \\
\hline 14 & Nitrofurantoin $(300 \mu \mathrm{g})$ & 0 \\
\hline 15 & Cotrimoxazole $(30 \mu \mathrm{g})$ & 92 \\
\hline 16 & Piperacillin $(110 \mu \mathrm{g})$ & 82 \\
\hline 17 & Doripinum () & 22 \\
\hline 18 & Tigecycline $(30 \mu \mathrm{g}$ & 58 \\
\hline 19 & Levofloxacin $(30 \mu \mathrm{g})$ & 66 \\
\hline 20 & Cepepime () & \\
\hline
\end{tabular}

\section{DISCUSSION}

In our present study, female patients were more affected (68\%) than male patients (32\%). Although infection from Pseudomonas can occur at any age, in our present study, the patient's age ranged from 51-70 years were more exaggerated in terms of male and female patients whereas the lowest incidence rate of infection was in between 1-20 years of age. All the other age groups had almost similar types of infection rate.

Pseudomonas associated infections having multidrug-resistant feature create an economic load as these are associated with high treatment costs and longer duration of hospital stay when compared to those associated with their drugsusceptible counterparts along with their substantial morbidity and mortality [13]. There is an utmost need for the proper detection and choice of an proper antibiotic to commence therapy for an optimized the clinical outcome [14]. In the current study, the Pseudomonas isolates were mainly collected from pus/wound samples followed by urine, sputum and ear infected area swabs which were had some form of similarity in relation to some previous studies [15, 16]. The maximum resistance was observed in amoxyclav, nitrofurantion and cotrimoxazole, and the minimum resistance was observed against colistin. The experiential rate of antibiotic resistance in our observation against aminoglycosides such as amikacin and gentamicin showed a same pattern when compared to some with previous studies [17,18]. Drug resistance against quinolones such as ciprofloxacin showed high sensitivity in the present study which was almost similar to the findings conducted by Fadeyi et al., 2005 [19]. Cephalosporins are regarded as anti-pseudomonal drugs, particularly ceftazidime which is a third generation cephalosporin and shows efficacy in such infections [14]. However, this drug also encountered some degree of resistance $(12 \%)$ in our study. The chief constraint of our study was that molecular depiction of resistant isolates particularly in case of identifying genes conferring resistant properties to the clinical isolates.

The susceptibility blueprint of antimicrobials against Pseudomonas has given us a guideline of the unrestrained use of antibiotics through this study. The sensible use of antibiotics by the concerned personnels such as doctors or health care professionals and attempt to control mishandling of antibiotics and procurement will aid in limiting the mounting rate of antibiotic resistance in the pathogenic microorganisms. Improper prescription of antibiotics for viral infections, against which they have no outcome or antibiotic employ for these conditions are pointless. Coherent drug policy should be in 


\section{International Advanced Research Journal in Science, Engineering and Technology}

Vol. 7, Issue 12, December 2020

\section{DOI 10.17148/IARJSET.2020.71201}

exercise before prescribing the effective antibiotics to the country [20]. Antibiotic management should track certain nominal rations [21].

\section{CONCLUSION}

Pseudomonas spp. remains a worldwide cause of nosocomial infections as well as causing life-threatening diseases such as pneumonia, meningitis, endocarditis, endophthalmitis, external otitis and septicemia [22]. In conclusion, our study emphasizes the development of public awareness regarding the prevention and spread of pseudomoad infection. Constant monitoring of the antimicrobial susceptibility pattern of Pseudomonas isolates for the selection of right therapy is also very much mandatory. The at hand circumstances of antimicrobial resistance in Bangladesh should be monitored critically, otherwise, it will become an irrepressible trouble not only in Bangladesh but also global in the days to come.

\section{ACKNOWLEDGMENT}

Heartfelt thanks and sincere appreciation to the Department of Microbiology, Stamford University, Bangladesh for necessary support while conducting the study.

\section{REFERENCES}

[1]. J. Tadvi, T.B. Javadekar, R. Bhavsar and N. Garala, Prevalence \& antibiogram of Pseudomonas aeruginosa at SSG Hospital, Baroda, Gujarat, India. J Res Med Dent Sci, 3 : 204-7, 2017.

[2]. S. Rao and S. Subbarayudu, Surveillance of Pseudomonas in COPD patients in a tertiary care hospital. Int J Res Med Sci, 3:1209-12, 2017.

[3]. R.R. Prasad, V. Shree, R. Kumar, K. Kala and Kumar P, Prevalence and antibiotic sensitivity of Pseudomonas aeruginosa isolated from CSOM in NMCH, Patna, India. Int J Curr Microbiol App Sci, 6:2912-6, 2017.

[4]. E. Kalantar, S. Taherzadeh, T. Ghadimi, F. Soheili, H. Salimizand and A. Hedayatnejad, Pseudomonas aeruginosa, an emerging pathogen among burn patients in Kurdistan province, Iran. Southeast Asian. J Trop Med Public Health, 43:712-7, 2012.

[5]. J. Dreier and P. Ruggerone, Interaction of antibacterial compounds with RND efflux pumps in Pseudomonas aeruginosa Front microbial, 6: 660, 2015.

[6]. National Nosocomial Infections Surveillance System. NNIS report, data summary from Jan 1990- May 1999. Am J Infect Contr, 27: 520-532, 1999.

[7]. N.M. Kawser, N.K. Khan, A.S.M. Rahman and E.A. Mondol, A study on nosocomial infections and antibiotic resistance pattern of the isolates in ICU patients. BAFMJ, 2: 9-13, 2002.

[8]. Guidance on regulations for the transport of infectious substances, World Health Organization, USA, 2009-10.

[9]. N.R. Kreig, J.G. Holt and D.H. Bergey, Manual of Systematic Bacteriology. 1st ed. East Preston street, Baltimore, 1984.

[10]. J.G. Collee, B.P. Marmion and A.G. Fraser, Practical Medical Microbiology. 14th ed. Churchill Livingstone, New York, 1996.

[11]. J.G. Collee, R.S. Miles and B. Watt, Tests for identification of bacteria. In Mackie and McCartneyPractical Medical Microbiology. 14th edition,

JG. Collee, AG.Fraser, BP Marmion, A Simmons (Eds.), pp.131-49,166-7. Churchill Livingstone: New York, 1996.

[12]. A.W. Bauer, W.M. Kirby, J.C, Sherris and M. Turck, Antibiotic susceptibility testing by a standardized single disk method. Ameri. J. Clin. Pathol, 45(4): 493-496, 1966.

[13]. P.D.Mauldin, C.D. Salgado, I.S. Hansen, D.T. Durup and J.A. Bosso, Attributable hospital cost and length of stay associated with health careassociated infections caused by antibiotic-resistant Gram-negative bacteria. Antimicrob Agents Chemother, 54 : 109-15, 2010.

[14]. K. Minu, K. Surbhi, B. Nidhi, M. Rajesh and M. Purva, Pathogen burden \& associated antibiogram of Pseudomonas spp. in a tertiary care hospital of India. Indian J Med Res, 149(2):295-298, 2019.

[15]. K.M. Angadi, M. Kadam and M.S.Modakn, Detection of Antibiotic Resistance in Pseudomonas aeruginosa Isolates With Special Reference to Metallo $\beta$-Lactamases From a Tertiary Care Hospital In Western India. International Journal of Microbiology Research, 14(7):295-8, 2012.

[16]. F. Anjum and A. Munir, Susceptibility Pattern of Pseudomonas aeruginosa against Various Antibiotics. African Journal of Microbi-ology Research, 4(10) 1005-12, 2010.

[17]. E.S. Amadi, P.N. Uzoaru, I . Orji and A. A.Nwaziri, Antibiotic resistance in clinical isolates of P. aeruginosa in Enugu and Abakalilki, Nigeria. Internet J Infect Dis, 8:2, 2009.

[18]. G.T. Jombo, P. Jonah and J.A.Ayeni, Multiple resistant Pseudomonas aeruginosa in contemporary medical practice: Findings from urinary isolates at a Nigerian university teaching hospital. Niger J Physiol Sci, $23: 105-9,2008$.

[19]. A. Fadeyi, A.A. Akanbi, C. Nwabuisi and B. A. Onile, Antibiotic disc sensitivity pattern of Pseudomonas aeruginosa isolates obtained from clinical specimens in Ilorin, Nigeria. Afr J Med Sci, 34:303-6, 2005

[20]. A. Aseffa and G. Yohhannes, Antibiotic Sensitivity of Staphylococcus Aureus and Escherichia Coli Strains Isolated in Gondar, Ethiopia. T Doctor, 15: 27(2):121-2, 1997.

[21]. E. Siam, S.N. Hoque, T. Jabin, M.I.Hossain, M. Asaduzzaman and M.A. Uddin, Determination of the Antibiotic Susceptibility Pattern of Clinical Isolates of Staphylococcus aureus Collected from Various Diagnostic Centers of Dhaka City, Bangladesh. International Advanced Research Journal in Science, Engineering and Technology, 116-121, 2020

[22]. P.B. Gerald, B. Ricardo, F. Victor and J. Leena, Infections Caused by Pseudomonas aeruginosa, Reviews of Infectious Diseases, Volume 5, Issue 2, March 1983, Pages 279-313. 